Review Article

\title{
FAST DISSOLVING TABLET USING SOLID DISPERSION TECHNIQUE: A REVIEW
}

\author{
PRATIK SWARUP DAS*, SUSHMA VERMA, PUJA SAHA \\ Pharmacy Institute, Noida Institute of Engineering and Technology \\ Email: pratikswarupdas@gmail.com
}

Received: 22 Aug 2017, Revised and Accepted: 13 Oct 2017

\begin{abstract}
Fast dissolving tablets are also called as mouth-dissolving tablets, melt-in mouth tablets, orodispersible tablets, quick dissolving etc. Fast dissolving tablets are those when put on tongue disintegrate instantaneously releasing the drug, which dissolve or disperses in the saliva. The faster the drug dissolved into solution, quicker the absorption and onset of clinical effect. Oral routes of drug administration have wide acceptance up to 50-60\% of total dosage forms. Fast dissolving tablet containing solid dispersion was developed to improve the dissolution of drug and stability of solid dispersion. They are disintegrating and/or dissolve rapidly in the saliva without the need for water. Thus it is regarded as the safest, most convenient and most economical method of drug delivery having the highest patient compliance. The later part of the article focus on the progress in methods of manufacturing, evaluation and various latest technologies involved in the development of Fast dissolving tablets. Solid dispersion is basically a drug-polymer two-component system; the drug-polymer interaction is the determining factor in its design and performance. It also discusses about modern characterization technique to characterize solid dispersion. In this review, it is intended to discuss the recent advances related on the area of solid dispersion technology. Different methods are also been used for preparation of solid dispersions such as Melting method Solvent method, Melting solvent method, Melt extrusion method, lyophilisation Technique, Melt Agglomeration Process, The Use Of Surfactant, Electro spinning and Super Critical Fluid Technology. The introduction of fast dissolving dosage forms has solved some of the problems encountered in administration of drugs to the pediatric and elderly patient, which constitutes a large proportion of the world's population. Solid dispersions have attracted considerable interest as an efficient means of improving the dissolution rate and hence the bio availability of a range of poorly watersoluble drugs. The focus of one part of the review article is based on solid dispersion mainly advantages, disadvantages, types, the method of preparation, and characterization of the solid dispersion at laboratory and industrial level.
\end{abstract}

Keywords: Solid dispersion technique, Fast dissolving tablet

(C) 2017 The Authors. Published by Innovare Academic Sciences Pvt Ltd. This is an open access article under the CC BY license (http://creativecommons.org/licenses/by/4.0/ DOI: http://dx.doi.org/10.22159/ijcpr.2017v9i6.23435

\section{INTRODUCTION}

Tablet is the most popular among all dosage forms existing today because of its convenience of self administration, compactness and easy manufacturing. Fast dissolving dosage forms can be disintegrated, dissolved, or suspended by saliva in the mouth Fast dissolving tablets are useful in patients, like pediatric, geriatric, bedridden, or mentally disabled, who may face difficulty in swallowing conventional tablets or capsules leading to ineffective therapy, with persistent nausea, sudden episodes of allergic attacks, or coughing for those who have an active life style. Fast dissolving tablets are also applicable when local action in the mouth is desirable such as local anesthetic for toothaches, oral ulcers, cold sores, or teething, and to those who cannot swallow intact sustained action tablets/capsules. The rate of absorption and the extent of bioavailability for such insoluble hydrophobic drug are controlled by the rate of dissolution [1]. Hence, an attempt has been made to increase the dissolution of such poorly water soluble drugs. Techniques that have commonly been used to improve dissolution and bioavailability of poorly water-soluble drugs, in general, include micronization, the use of surfactant, and the formation of solid dispersions. Solid dispersions are used to increase their effectiveness and simultaneously reduce their doses and hence the toxic effect. Solid dispersions traditionally have been used as an effective method to improve the dissolution properties and bioavailability of poorly water soluble drugs. Many substances can be employed as carriers to prepare solid dispersions. Among the popular carriers used in the formation of solid dispersion are polyethylene glycol and mannitol. Both polymers are often employed as a vehicle due to its low toxicity, low melting point, rapid solidification rate, high aqueous solubility. These and other properties make them a very suitable vehicle for formulations into dosage forms.

\section{Solid dispersions}

SD refers to the group of solid products consisting of at least two different components, generally a hydrophilic matrix and a hydrophobic drug; the matrix can be either crystalline or amorphous [1]. The solid dispersion was introduced to overcome the low bioavailability of lipophilic drugs by forming a eutectic mixture of drugs with water soluble carriers. Approximate $40 \%$ of new chemical entities (NCE) being synthesized by combinatorial screening programs possessing superior pharmacological activities are poorly soluble, which is a great obstacle in formulation development [2]. Biopharmaceutical classification system (BCS) highlights the dissolution as rate limiting step for oral absorption of BCS class II and class IV drugs. BCS class II and class IV drugs have low solubility.

\section{Advantages of solid dispersion [3-5]}

1. Particles with reduced particle size

2. Particles with improved wettability

3. Particles with higher porosity

4. Drugs in amorphous state

Disadvantages of solid dispersions [6]

The major disadvantages of SDs are related to their instability Moisture and temperature have more of deteriorating effect on solid dispersions than on physical mixtures.

\section{Types of solid dispersion [7-10]}

On the basis of molecular arrangement, six types of molecular dispersion can be distinguished.

1. Solid eutectic mixture: A simple eutectic mixture consists of two components which are completely miscible in liquid state but to a limited extend in solid state. These are prepared by rapid solidification of fused melt of two components.

2. Solid solution: In a solid solution, the two components crystallize together in a homogeneous one phase system. On the 
extend of miscibility of two components, solid solution is classified as continuous and discontinuous. In continuous solid solution, the two components are miscible in the solid state in all proportions. In discontinuous solid solutions, the solubility of each of the components in the other component is limited.

3. Glass solution and suspension: A glass is a homogenous glassy system in which solute dissolves in the glassy system. A glass suspension refers to a mixture in which precipitated particles are suspended in a glassy solvent.

4. Amorphous precipitation's in crystalline carrier: In the group of dispersions drug is precipitated out amorphous form while in simple eutectic mixture it is in crystalline form. Example: Sulfathiazole in crystalline urea.

5. Continuous solid solutions: In a continuous solid solution, the components are miscible in all proportions. Theoretically, this means that the bonding strength between the two components is stronger than the bonding strength between the molecules of each of the individual components. Solid solutions of this type have not been reported in the pharmaceutical world till date.

6. Discontinuous solid solutions: In the case of discontinuous solid solutions, the solubility of each of the components in the other component is limited. Due to practical considerations, it has been suggested by Goldberg et al. that the term `solid solution' should only be applied when the mutual solubility of the two components exceeds $5 \%$.

\section{Preparation of solid dispersions [11-15]}

Various preparation methods for solid dispersions have been reported in literature.

\section{A. Fusion method}

The fusion method is sometimes referred to as the melt method. The first solid dispersions created for pharmaceutical applications were prepared by the fusion method. The dispersion consisted of sulfathiazole and urea as a matrix which was melted using a physical mixture at the eutectic composition, followed by a cooling step. The eutectic composition was chosen to obtain simultaneous crystallization of drug and matrix during cooling. Poly ethylene glycol (PEG) is a hydrophilic polymer often used to prepare solid dispersions with the fusion method.

\section{B. Hot melt extrusion}

Melt extrusion is essentially the same as the fusion method except that intense mixing of the components is induced by the extruder. When compared to melting in a vessel, the product stability and dissolution are similar, but melt extrusion offers the potential to shape the heated drug-matrix mixture into implants, ophthalmic inserts, or oral dosage forms. Compared to the traditional fusion method, this technique offers the possibility of continuous production, which makes it suitable for large-scale production.

\section{Solvent evaporation method}

In this method, the physical mixture of the drug and carrier is dissolved in a common solvent, which is evaporated until a clear, solvent free film is left. The film is further dried to constant weight. The first step in the solvent method is the preparation of a solution containing both matrix material and drug. The second step involves the removal of solvent(s) resulting in formation of a solid dispersion. Mixing at the molecular level is preferred, because this leads to optimal dissolution properties.

The main advantage of the solvent method is thermal decomposition of drugs or carriers can be prevented because of the relatively low temperatures required for the evaporation of organic solvents.

However, some disadvantages are associated with this method such as

1) The higher cost of preparation.

2) The difficulty in completely removing liquid solvent.

3) The possible adverse effect of traces of the solvent on the chemical stability
4) The selection of a common volatile solvent.

5) The difficulty of reproducing crystal form.

\section{Supercritical fluid methods}

Supercritical fluid methods are mostly applied with carbon dioxide $\left(\mathrm{CO}_{2}\right)$, which is used as either a solvent for drug and matrix or as an anti-solvent. When supercritical $\mathrm{CO}_{2}$ is used as solvent, matrix and drug are dissolved and sprayed through a nozzle, into an expansion vessel with lower pressure and particles are immediately formed. The adiabatic expansion of the mixture results in rapid cooling. This technique does not require the use of organic solvents and since $\mathrm{CO}_{2}$ is considered environmentally friendly, this technique is referred to as „solvent freè. The technique is known as Rapid Expa nsion of Supercritical Solution (RESS). The application of this technique is very limited, because the solubility in $\mathrm{CO}_{2}$ of most pharmaceutical compounds is very low $(<0.01 \mathrm{wt}-\%)$ and decreases with increasing polarity. Therefore, scaling up this process to kilogram-scale will be impractical.

\section{E. Melting solvent method}

It involves preparation of solid dispersions by dissolving the drug in a suitable liquid solvent and then incorporating the solution directly into the melt of polyethylene glycol, which is then evaporated until a clear, solvent free film is left. The film is further dried to constant weight. The $5-10 \%(\mathrm{w} / \mathrm{w})$ of liquid compounds can be incorporated into polyethylene glycol 6000 without significant loss of its solid property. It is possible that the selected solvent or dissolved drug may not be miscible with the melt of the polyethylene glycol.

\section{F. Lyophilization technique}

Lyophilization involves the transfer of heat and mass to and from the product under preparation. This technique was proposed as an alternative technique to solvent evaporation. Lyophilization has been thought of a molecular mixing technique where the drug and carrier are co-dissolved in a common solvent, frozen and sublimed to obtain a lyophilized molecular dispersion.

\section{G. Spray freeze drying}

Dissolve the drug in a solvent at a fixed concentration and carrier in water. Mix the solution in a ratio of $40 / 60 \mathrm{v} / \mathrm{v}$. spray the solutions through the nozzle into liquid nitrogen. Set the liquid feed rate and atomizing air flow. Position the outlet of the nozzle at about $10 \mathrm{~cm}$ above the liquid nitrogen. Hot water is pumped through the jacket of the nozzle in order to avoid freezing of the solution inside the nozzle. Transfer the resulting suspension (frozen droplets of the solution in liquid nitrogen) to the lyophilizer. Lyophilization procedure is started as soon as all liquid nitrogen is evaporated.

\section{H. Melt agglomeration process}

The utility of the surfactant systems insolubilization is very important. Adsorption of surfactant on the solid surface can modify their hydrophobicity, surface charge, and other key properties that govern interfacial processes such as flocculation/dispersion, floatation, wetting, solubilization, detergency, and enhanced oil recovery and corrosion inhibition. Surfactants have also been reported to cause solvation/plasticization, manifesting in the reduction of melting the active pharmaceutical ingredients, glass transition temperature and the combined glass transition temperature of solid dispersions. Because of these unique properties, surfactants have attracted the attention of investigators for the preparation of solid dispersions.

\section{Electrospinning}

Electrospinning is a process in which solid fibres are produced from a polymeric fluid stream solution or melt delivered through a millimeter-scale nozzle. This process involves the application of a strong electrostatic field over a conductive capillary attaching to a reservoir containing a polymer solution or melt and a conductive collection screen. Upon increasing the electrostatic field strength up to but not exceeding a critical value, charge species accumulated on the surface of a pendant drop destabilize the hemispherical shape into a conical shape (commonly known as Taylor scone). Beyond the 
critical value, a charged polymer jet is ejected from the apex of the cone (as a way of relieving the charge built-up on the surface of the pendant drop). The ejected charged jet is then carried to the collection screen via the electrostatic force. The Columbic repulsion force is responsible for the thinning of the charged jet during its trajectory to the collection screen. The thinning down of the charged jet is limited. If the viscosity increases, the charged jet is dried.

\section{Ideal properties of FDT [16-17]}

1. Require no water for oral administration.

2. Have a pleasing mouth feel.

3. Have an acceptable taste masking property.

4. Be harder and less friable

5. Leave minimal or no residue in mouth after administration

6. Exhibit low sensitivity to environmental conditions (temperature and humidity).

7. Allow the manufacture of tablet using conventional processing and packaging equipment

\section{Advantages of fast dissolving tablets [18-21]}

1. Convenient and easy to administer as does not require water for oral administration.

2. Durable and sufficient strength to withstand the rigors of the manufacturing process and manufacturing handling.

3. Pleasant mouth feel.

4. Insensitive to environmental conditions such as humidity and temperature.

5. Improved taste without any residue in the mouth after disintegration.

6. Adaptable and amenable to existing processing and packaging machinery.

7. Cost effective.

8. Compatible with taste masking.

9. Patient having difficulty in swallowing tablet can easily administer this type of dosage form.

\section{Disadvantage of fast dissolving tablets [22-23]}

1. Fast dissolving tablet is hygroscopic in nature so must be keep in dry place.

2. Some time it possesses mouth feeling.

3. It is also show the fragile, effervesces granules property.

4. FDT requires special packaging for properly stabilization and safety of stable product. 2

Conventional techniques used for preparation of FDDDS [24-28]

\section{A. Disintegrant addition}

Disintegrant addition technique is one popular technique for formulating Fast-dissolving tablets because of its easy implementation and cost-effectiveness. The basic principle involved in formulating Fast-dissolving tablets by disintegrant addition technique is addition of superdisintegrants in optimum concentration so as to achieve rapid disintegration along with the good mouth feel. Microcrystalline cellulose and low substituted hydroxyl propylcellulose were used as disintegrating agents in the range of 8:2-9.1 to prepare fast dissolving tablet.

\section{B. Freeze drying}

Lyophilization is a pharmaceutical technology which allows drying of heat sensitive drugs and biological at low temperature under conditions that allow removal of water by sublimation.

\section{Moulding}

In this method, molded tablets are prepared by using water soluble ingredients so that the tablets dissolve completely and rapidly. The solvent is then removed by air-drying.

\section{Sublimation}

The slow dissolution of the compressed tablet containing even highly water-soluble ingredients is due to the low porosity of the tablets. The volatile materials were then removed via sublimation, which generates porous structures. Additionally, several solvents (e. g. cyclohexane, benzene) can be also used as pore forming agents.

\section{E. Spray-drying}

Spray drying can produce highly porous and fine powders that dissolve rapidly. The formulations are incorporated by hydrolyzed and non hydrolyzed gelatins as supporting agents, mannitol as bulking agent, sodium starch glycolate or cross carmellose sodium as disintegrating and an acidic material (e. g. citric acid) and/or alkali material (e. g. I sodium bicarbonate) to enhance disintegration and dissolution.

\section{F. Mass-extrusion}

This technology involves softening the active blend using the solvent mixture of water soluble polyethylene glycol, using methanol.

\section{G. Direct compression}

It is the easiest way to manufacture tablets. Conventional equipment, commonly available excipients and a limited number of processing steps are involved in direct compression.

\section{CONFLICT OF INTERESTS}

Declared none

\section{REFERENCES}

1. Hannan PA, Khan JA, Khan A, Safiullah S. Oral dispersible system: a new approach in drug delivery syste. Indian J Pharm Sci 2016;78:2-7.

2. Patel TS, Sengupta M. Fast dissolving tablet technology. World J Pharm Sci 2017;2:485-508.

3. Bhowmik D, Chiranjib B, Krishnakanth, Pankaj, Chandira RM. Fast dissolving tablet: an overview. J Chem Pharm Res 2016;1:163-77.

4. Siddiqui N, Garg G, Sharma PK. Fast dissolving tablets: preparation, characterization and evaluation: an overview. Int J Pharm Sci 2015;2:87-96.

5. Kumari S, Visht S, Sharma PK, Yadav RK. Fast dissolving drug delivery system: a review article. J Pharm Res 2016;3:1444-9.

6. Mohanachandran PS, Sindhumol PG, Kiran TS. Superdisintegrants: an overview. Int J Pharm Sci Rev Res 2015;6:105-9.

7. Deshmukh VN. Mouth dissolving drug delivery system: a review. Int J Pharm Tech Res 2016;4:412-21.

8. Leunar C, Dreessan J. Improving drug solubility for oral delivary using solid dispersion. Eur J Pharm Biopharm 2014;50:47-60.

9. Gupta DK, Bajpai M, Chatterjee DP. Fast mouth is dissolving disintegrating tablet and patient counselling points for FDDTSa review. Int J Res Dev Pharm Life Sci 2014;3:949-58.

10. Nautiyal U, Singh S, Singh R, Gopal, Kakar S. Fast dissolving tablets as a novel boon: a review. J Pharm Chem Biol Sci 2014;2:5-26.

11. Kaur T, Gill B, Kumar S, Gupta GD. Mouth dissolving tablets: a novel approach to drug delivery. Int J Curr Pharm Res 2011;1:1-7.

12. Nagar P, Singh K, Chauhan I, Verma M, Yasir M, Khan A. Orally disintegrating tablets: formulation, preparation techniques and evaluation. J Appl Pharm Sci 2015;4:35-45.

13. Kumaresan C. Orally disintegrating tablet-mouth dissolving, sweet taste and target release profile. Pharmaceutical 2015;6:25-36.

14. Eun JK. Preparation of solid dispersion of felodipine using a solvent wetting method. Eur J Pharm Biopharm 2016;64:200-5. 
15. Kazi PA, Gholve SB, Kazi SN. Review article solid dispersion: an evergreen method for solubility enhancement of poorly water soluble drugs. Int J Res Pharm Chem 2014;4:906-18.

16. Parkash V, Maan S, Deepika, Yadav SK, Hemlata, Jogpal V. Fast disintegrating tablets: opportunity in drug delivery system. J Adv Pharm Technol Res 2014;2:223-35.

17. Velmurugan S, Vinushitha S. Oral disintegrating tablets: an overview. Int J Chem Pharm Sci 2016;1:1-12.

18. Argade GD, Magar DD, Saudagar RB. Review article on solid dispersion as solubility enhancement technique for poorly water soluble drugs. J Adv Pharm Edu Res 2013;3:427-39.

19. Singh J, Walia M, Harikumar SL. Formulation and evaluation of fast dissolving tablets of rosuvastatin. J Drug Delivery Ther 2013;3:148-55.

20. Dixit AK, Singh RP, Singh Stuti. Formulation and evaluation of solid dispersion of amlodipine besylate. Int J Res Pharm Biomed Sci 2015;3:960-6.

21. Sameer Singh, Raviraj Singh Baghel, Lalit Yadav. A review on solid dispersion. Int J Pharm Life Sci 2016;2:1078-95.
22. Varun RJ, Venkateshwarlu L, Srikanth L. Combinational products: a regulatory review. Int J Pharm Sci Rev Res 2015;5:41-51.

23. Chauhan R, Virmani S, Suman P. Quantitative method development and validation of sulfasalazine in tablet dosage form by uv-spectroscopy. Int J Pharm Sci Rev Res 2015;2:120-9.

24. KV, Raj GB, Ravishanker D, Kumar CA. Preparation and evaluation of montelukast oral dispersible tablets by direct compression method. Int Res J Pharm 2014;7:315-8.

25. Yang D, Kulkarni R, Behme RJ, Kotiyan PN. Effect of the melt granulation technique on the dissolution characteristics of griseofulvin. Int J Pharm 2015;329:72-80.

26. Khan $\mathrm{AB}$, Tripuraneni A. Fast dissolving tablets-a novel approach in drug delivery. Rguhs J Pharm Sci 2014;1:7-16.

27. Chowdary YA, Soumya M, Madhubabu M, Aparna K, Himabindu P. A review on fast dissolving drug delivery systems-A pioneering drug delivery technology. Bull Environ Pharmacol Life Sci 2015;1:8-20.

28. Abdulraheman ZS, Patel MR, Patel KR. A review on immediate release tablet. Int J Univers Pharm Bio Sci 2016;3:93-113. 